\title{
Los Derechos Humanos y el valor supremo de la paz como presupuestos del reconocimiento democrático: una refiexión para la Colombia del posconflicto*
}

\author{
Kevin Alexander Jaramillo Castrillón \\ Universidad de Medellín, Medellín, Colombia \\ jaramillo@udem.edu.co \\ Rodrigo Antonio Rodríguez Palacio \\ Universidad de Medellín, Medellín, Colombia \\ rodantorodriguez@gmail.com
}

\section{RESUMEN}

En el marco de la tradición política occidental, los derechos han representado un discurso legitimador de los sistemas democráticos. Su asimilación política e institucional ha permitido auscultar las prácticas democráticas desde una correspondencia discursiva que contempla las garantías normativas y jurídicas como recursos para el aseguramiento de la dignidad del hombre en sociedad. En ese sentido, se analizan reflexiones en torno a expresiones de los derechos enmarcados en una reconstrucción histórica de los Derechos Humanos y su función política como fundamento de las relaciones políticas internacionales, así como el lugar que ocupa la paz entendida como un valor democrático supremo. Esto permitirá, en un primer momento, hacer tránsito por los momentos históricos más importantes en la configuración de los Derechos Humanos como discurso político señalando su acervo histórico en la tradición democrática liberal y de las tensiones filosóficas, sociales y normativas que ello implica para, en un segundo momento, resaltar cuáles son los presupuestos políticos de su defensa frente a las contingencias particulares de la Colombia del posconflicto.

Palabras clave: Derechos Humanos; democracia; discurso político; reconocimiento; dignidad humana; Colombia; democracia liberal; paz; posconflicto.

Cómo citar: Jaramillo Castrillón, K. y Rodríguez Palacio, R. A. (2018). Los Derechos Humanos y el valor supremo de la paz como presupuestos del reconocimiento democrático: una reflexión para la Colombia del posconflicto. Ciencias Sociales y Educación, 7(14), 165-186. DOI: https://doi.org/10.22395/csye.v7n14a9 Recibido: 21 de mayo de 2018.

Aprobado: 14 de agosto de 2018. 


\section{Human Rights and the Supreme Value of Peace as a Presupposition of Democratic Recognition. A Reflection for Peace in Post-conflict}

\section{ABSTRACT}

In the framework of the western political traditions, rights have represented a legitimacy discourse for democratic systems. Its political and institutional absorption has allowed the perception of democratic practices from a discursive correspondence that contemplates the legal and normative guarantees as resources for the reassurance of human dignity in society. Thus, this article analyzes some reflections around expressions of rights framed in a historical reconstruction of Human Rights and its political function as the foundation of international political relations, as well as the role of peace, understood as a supreme democratic value. All this will allow, in a first moment, a pathway for the most important historical moments in the shaping of Human Rights as a political discourse by pointing its historical heritage in the liberal democratic tradition and the philosophical, social and normative tensions that it implies in order to, in a second moment, highlight which are the political presumptions in its defense from the particular contingencies of a post-conflictual Colombia.

Keywords: Human Rights; democracy; political discourse; recognition; human dignity; Colombia; liberal democracy; peace; post-conflict.

\section{Os Direitos Humanos e o valor supremo da paz como pressupostos do reconhecimento democrático: uma refiexão para a Colômbia do pós-conflito}

\section{RESUMO}

No âmbito da tradição política ocidental, os direitos representam um discurso legitimador dos sistemas democráticos. Sua assimilação política e institucional permite considerar as práticas democráticas a partir de uma correspondência discursiva que contempla as garantias normativas e jurídicas como recursos para o asseguramento da dignidade do homem em sociedade. Nesse sentido, são analisadas reflexões sobre expressões dos direitos delimitados em uma reconstrução histórica dos Direitos Humanos e sua função política como fundamento das relações políticas internacionais, bem como o lugar que a paz ocupa, entendida como um valor democrático supremo. Isso permitirá, em um primeiro momento, percorrer os momentos históricos mais importantes na configuração dos Direitos Humanos como discurso político e indicar seu acervo histórico na tradição democrática liberal e na configuração das tensões filosóficas, sociais e normativas que isso implica para, em um segundo momento, ressaltar quais são os pressupostos políticos de sua defesa ante as contingências particulares da Colômbia do pós-conflito.

Palavras-chave: Direitos Humanos; democracia; discurso político; reconhecimento; dignidade humana; Colômbia; democracia liberal; paz; pós-conflito. 


\section{Introducción}

Los Derechos Humanos, desde su comprensión en la tradición política de Occidente, se han erguido como el discurso que, en última instancia, ha dado forma y se ha puesto a la base del funcionamiento de todos los sistemas democráticos como el pilar que ofrece las garantías defensoriales de la dignidad humana. Su papel en el entendimiento de las actuales formas de la política que se desarrollan en el panorama internacional resulta capital para comprender el funcionamiento de siglos y siglos de pugnas por el reconocimiento político de los territorios que configuran el planisferio actual y las repercusiones de su distribución desde la polis griega hasta los actuales sistemas de representación.

Sobre esta base de entendimiento, en las líneas que siguen, se presentarán dos momentos importantes para el entendimiento del discurso de los Derechos Humanos y su función defensorial en la dignificación de la persona humana. Así, en un primer momento, se presentará una reconstrucción histórica que permita entender la configuración del discurso de los Derechos Humanos y su servicio en el establecimiento de las actuales democracias liberales. Luego, se presentará el caso más cercano de dicho servicio en el contexto particular del Estado colombiano, a saber, el acuerdo de paz entre el Gobierno de Colombia y las Fuerzas Armadas Revolucionarias de Colombia (FARC) para llevar a su fin las confrontaciones bélicas entre estas dos partes, y una breve reflexión al respecto de la representación de dicho discurso en la defensa de la dignidad humana y sus alcances y pertinencia en las actuales problemáticas democráticas en el panorama político internacional.

\section{Los Derechos Humanos y la democracia}

El fenómeno de lo político, como fenómeno humano, ha sufrido transformaciones sustanciales a lo largo del tiempo. Atrás quedaron las marcas identitarias de los griegos y su afamada polis, ese lugar entrañable que desde relatos de héroes con destinos trágicos le dieron vida a una cultura que proliferó políticamente en el siglo V, su siglo de oro. La época de Pericles logró conmocionar los cimientos de la historia misma al materializar un ideal de identificación con el otro como sustrato que permitiría lo social, lo político y lo cultural. Y cómo no lograrlo cuando ese periodo representó la consolidación de disertaciones infinitas de pensadores que, al son de hoy, todavía ofrecen las más controvertidas lecturas de lo que representa la naturaleza en el orden de las cosas. Esa Grecia, cuna de la cultura occidental, le ofrecerá a la historia un primer referente de reconocimiento que permitirá leer la que hasta ahora es la forma más popular, tradicional y política de las expresiones sociales, la democracia.

Y esa democracia, que ha sufrido transformaciones igual de sustanciales, alcanza entre los siglos XVII y XVIII su época dorada, de la mano de fenómenos 
filosóficos y sociopolíticos innumerables que aportaron a la modificación del mapa mundial. Del racionalismo alemán en Kant y Hegel y las premisas emancipatorias de su visión antropológica que le concede al hombre la capacidad de pensar-se como un movimiento de su conciencia, hasta el establecimiento institucional del Estado moderno; de la libertad como presupuesto político, hasta la industrialización, en últimas, condiciones sine qua non esa nueva polis llamada democracia no habría alcanzado su madurez.

Esta polis ya no se enmarca en los límites territoriales de las ciudades-nación de la antigüedad, sino del reconocimiento identitario a raíz de esa autonomía y del derecho a ser individuos y colectivos emancipados. Naturalmente, este es el rostro más generoso de la democracia, ya que, cabe la aclaración, irremediablemente esos procesos de autoconformación e identidad que configuran el nuevo mapa mundial, después de las revoluciones burguesas, solo será posible tras siglos y siglos de innumerables confrontaciones. Ahora bien, podría pensarse que la descripción del Estado moderno representa el último estadio de reconocimiento democrático, nada más lejos de la realidad.

Con pensadores como Kant, prolifera la idea de que la distribución espaciotemporal de los Estados-nación no resuelve los conflictos humanos como se fundamenta en las bases de su justificación histórica y social. Ese marco de entendimiento democrático ha alcanzado niveles insospechados. El triunfo del capitalismo, el fenómeno de la globalización, la proliferación de los medios masivos e intangibles de comunicación -y del trabajo- han consolidado la imagen de una política de niveles planetarios, no solo que alcance y responda al desaforado desarrollo de la industrialización y modernización, sino que mantenga viva la consolidación de un mundo sin conflictos humanos donde los límites territoriales de los Estados caigan ante la visualización de un nuevo ciudadano, el ciudadano del mundo.

Este apartado no pretende hacer apología del cosmopolitismo, pretende abordar reflexivamente uno de los elementos que han catapultado la comprensión global de lo político, a saber, los Derechos Humanos, entendiendo este como un discurso que, de múltiples maneras y desde múltiples perspectivas, ha consolidado la razón política planetaria como respuesta a las nuevas contingencias sociales. Si bien los Derechos Humanos no son el único organón que ha servido a dicha consolidación, sí es uno de los más importantes en términos históricos y sociales, al punto que, si bien nace y se consolida desde la fundamentación misma de los grandes Estados padres de la democracia moderna, hoy día su aceptación y despliegue se han convertido en medidores de legitimidad de los sistemas políticos. Por esta razón, aquí se pretende, en el primer momento, auscultar los presupuestos políticos de los Derechos Humanos desde las dos perspectivas que lo consolidan como organón político de las naciones, a saber, el 
iusnaturalismo y el positivismo jurídico, para, en un segundo momento, develar la fuerza política de los mismos como una nueva comprensión de lo democrático, de sus alcances, de su correspondencia política y de su funcionalidad para pensar las contingencias que asisten a la política actual.

Los Derechos Humanos se han convertido en un elemento indiscutible de los sistemas democráticos. A la distribución de las fuerzas del poder, los valores de libertad e igualdad, el acceso al voto, la delegación o representación, las contiendas políticas y los lenguajes normativos constitucionales, se suman los Derechos Humanos como un presupuesto característico de los sistemas democráticos. Si bien sus momentos de aparición son abismalmente diferentes, varios de sus presupuestos identitarios, de sus objetivos metodológicos y políticos encuentran una simetría enmarcada en la triada democracia-Estado de derecho- Derechos Humanos. En el papel, esta se confabula contra la proliferación de la barbarie con la pretensión de otorgarle al ser humano un posicionamiento social desprendido de las premisas emancipatorias de la modernidad y de la enunciación de los rasgos humanizadores como preceptos de identificación política (Angarita, 1997, p. 16).

Pero una cosa es clara: si bien los Derechos Humanos, el Estado de derecho y la democracia se fusionan en varios presupuestos de la vida sociopolítica de la contemporaneidad, el elemento sobresaliente que mantiene atada esta relación es la dignidad humana como el culmen del entendimiento político, esto es, aquellos presupuestos que, política y socialmente, permitirán que cualquier ser humano, en cualquier latitud del mundo, despliegue sus potencialidades hacia la consecución de una vida digna. Así pues, los Derechos Humanos abordarán aquellas libertades, derechos y garantías que históricamente se ganaron un puesto de privilegio en la tradición occidental por considerarse a la manera de garantías para el despliegue de la vida misma, en sus múltiples ámbitos: social, económico, político y cultural. Pero entonces, ¿de dónde emanan los Derechos Humanos y, sobre todo, de dónde deviene esa suerte de consenso entre las naciones frente a que sus postulados políticos, filosóficos y sociales persigan un índice mínimo de aquello que permite el despliegue de la vida digna del hombre? Si bien la respuesta a este interrogante evoca las variaciones en el entendimiento de las condiciones mínimas para el despliegue de la institucionalidad dentro de los Estados y de los mismos sistemas políticos, el consenso sobrevive.

Los fundamentos de dicho consenso corren por cuenta de que los Derechos Humanos han sido planteados en términos del entendimiento ético, histórico y político que actualmente se encuentra en el corazón del derecho internacional y del constitucionalismo pero, sobre todo, de su acervo histórico que erige desde la modernidad al liberalismo y la democracia. Desde este lugar de enunciación se tendrán en cuenta dos elementos centrales como fundamento de la vida 
política democrática a saber, la idea de que los Derechos Humanos engloban, resuelven y se remiten a la dignidad humana como presupuesto político, y una preocupación emulada desde las dos corrientes o perspectivas que le han dado forma a los Derechos Humanos: el iusnaturalismo y el positivismo jurídico.

\section{La historicidad de los Derechos Humanos}

Cuando se indaga por el fundamento historicofilosófico de los Derechos Humanos, la antigua Grecia aparece como uno de sus contextos más significativos. En la cuna de Occidente se percibe ya un debate sobre las condiciones de la dignidad humana presente en la que es considerada la tragedia por excelencia: la Antígona de Sófocles.

Esta historia desgarradora narra el desenlace de los hijos del rey Edipo; de Polinices y Eteocles muertos en combate uno por el otro, y de una Antígona enfrentada al Estado de Tebas, timoneado por Creonte, por el hecho de violar una norma que sentenciaba que el cuerpo de Polinices debería permanecer insepulto y expuesto a los perros y las aves de rapiña.

Ante la sentencia de Creonte, Antígona ofrece una de las muestras más contundentes de determinación política cuando, en violación consiente de la ley, decide enterrar a su hermano aduciendo que, si bien sus actos contradicen y violentan las normas del Estado, a su vez, su comportamiento entra en correspondencia con aquellos valores que son de mayor agrado a los dioses. En ultimas, negar al hermano muerto el debido cortejo fúnebre es un crimen que Antígona no está dispuesta a cometer, así ello implique contradecir los designios políticos de su pueblo y su propia muerte. Así entonces:

Contra los dioses infernales (in inferis), huella un derecho divino y no hay utilidad de la política tirana que lo justifique. En nombre de aquellas leyes que no son de hoy ni de ayer, sino de siempre, Antígona, en pugna con la ley humana por no quebrantar la ley divina, le lleva la contra al tirano, entierra simbólicamente a su hermano y salva aquel deber intocable, a costa de la propia vida (Sánchez Pacheco, 1981, p. 80)

En palabras de la misma Antígona:

Sin embargo, al irme, alimento grandes esperanza de llegar querida para mi padre y querida también para ti, madre, y para ti, hermano, porque, cuando vosotros estabais muertos, yo con mis manos os lavé y os dispuse todo y os ofrecí las libaciones sobre la tumba Y ahora, Polinices, por ocultar tu cuerpo, consigo semejante trato. Pero yo te honré debidamente en opinión de los sensatos. Pues nunca, ni aunque hubiera sido madre de hijos, ni aunque mi esposo muerto se estuviera corrompiendo, hubiera tomado sobre mí esta tarea en contra de la voluntad de los ciudadanos (Sófocles, 1981, p. 282).

Las palabras de Antígona escenifican, por un lado, el compromiso por la dignidad del otro como fundamento de sus acciones, incluso, en un contexto 
problemático que compromete seriamente su integridad y, por otro, el antiguo debate del derecho natural -escenificado en las leyes de los dioses a los cuales quiere honrar Antígona-y el derecho positivo -la norma punible que sentencia Creonte ante la muerte de los hijos de Edipo y la subsecuente prohibición de rendirle un sepulcro digno a Polinices-.

\section{Dos perspectivas filosóficas}

La tragedia de Sófocles introduce la exposición del derecho natural y su vínculo con la dignidad humana. En términos generales, el derecho natural se entiende como un conjunto de normas y principios jurídicos que se atribuyen a la propia naturaleza de la razón humana y que existen como principios inmutables y universales de su mera existencia. Estos buscan una correspondencia con aquellos elementos que son inherentes a la naturaleza humana y que no necesitan un reconocimiento normativo o la buena voluntad del legislador para ser reconocidos, ya que sus preceptos se desligan de la contemplación de la razón y la naturaleza que corresponden a la condición de existencia humana.

Si bien históricamente el derecho mantiene una interpretación recelosamente política, es innegable que cualquier objeto del conocimiento que pase por el medioevo tendrá un contacto, una interpretación o un uso político cristianizado, siendo el derecho natural uno de los más manoseados ya desde la religiosidad, ya desde la institucionalidad. Al respecto, aparecen las consideraciones de Santo Tomás de Aquino para quien el derecho natural tendrá una inmanencia divina disponible al uso social del hombre. El carácter de la ley divina permite el acceso de la racionalidad humana a la interpretación y participación del carácter divino de las leyes. De esta manera, la ley natural tendrá alcances universales, inmutables y eternos llamados a direccionar la vida del hombre y asegurar su existencia.

Por su parte, San Agustín será más directo en la fundamentación ontológica del derecho natural en contraposición al derecho de los hombres. La exposición llevada a cabo en su obra más afamada, La Ciudad de Dios, puede ser dividida en virtud de los objetos que la describen y la componen: la ciudad de los hombres y la ciudad de Dios; la historia de los hombres y la historia de dios. La naturaleza de los hombres y la naturaleza divina son tan abismalmente diferentes que podrían extraerse dos libros diferentes respecto a las características inherentes a cada naturaleza. Ahora bien, lo importante respecto al derecho natural es resaltar que, para este pensador, la naturaleza de la ley natural que deviene por precepto divino mantendrá una fuerza legitimada en las carencias mismas de la historia y la naturaleza del hombre, de donde esta ley eterna, omnisciente y verdaderamente justa tendrá un status superior e inviolable (Villegas, 2014, p. 97). 
Para no perder el norte de la exposición, se dirá que los dos grandes pensadores del medioevo señalan, a su manera, que el derecho natural alcanza su legitimidad política al hacer evidente que las contingencias sociales típicas de la historia humana emiten una naturaleza legislativa incipiente y arcaica arraigada en años y años de lucha por el poder, mientras que las leyes que emanan de la consideración divina permanecen inmutables gracias a su misma naturaleza.

Posterior al medioevo, la filosofía política se afinca en una nueva descripción del derecho natural, entendido como aquellas garantías que requiere un individuo para desarrollarse en la vida social: una garantía que emana, no de la naturaleza divina, sino de los presupuestos identificadores de la persona humana. Una descripción que lubrica el despliegue del hombre como ser social y ser de derechos; como ser que reclama libertad y condiciones para su despliegue. Lo interesante de esta descripción es comprender que la materialización de los derechos que despliegan la naturaleza humana es anterior al mismo reconocimiento político; en otras palabras, que la condición que permite la lectura de los derechos del hombre no necesita concesión normativa alguna de los sistemas políticos, por el contrario, estos se presentan por la sola condición de existencia del hombre (Villegas, 2014, p. 99).

Tras largas transformaciones políticas, sociales y culturales, más exactamente en el siglo XIX, ocurrió un cambio en la comprensión juridicopolítica que marcó el rumbo del fenómeno de lo político en Occidente: el positivismo jurídico. Esta comprensión selló una evolución ideológica en la filosofía y la ciencia política desde un giro conceptual de la naturaleza de las leyes, de las normas y de la justificación política de las mismas, cuyo fin fue ubicar al hombre y a su actividad política como ejes centrales de un análisis basado en los presupuestos lógicos de los métodos científicos. En todo caso, la legitimidad de la que se habla no fue un fenómeno inherente a la filosofía o la ciencia política, sino que tuvo serias repercusiones en las ciencias sociales en general, popularizando la idea de que los cuerpos sociales y, en general, las acciones del hombre podían ser contempladas bajo el rigor científico típico de las ciencias exactas.

Expresamente, la ciencia jurídica reconoce el triunfo de las normas sociales y de la concesión prescriptiva de los documentos políticos. Esta consideración parte de la consolidación de que el derecho como valor y principio político solo puede entenderse en los límites de su comprensión normativa. En otras palabras, la descripción del positivismo jurídico brinda una supremacía al formulismo de las normas jurídicas sobre los valores e ideales del iusnaturalismo y el derecho natural en general, de donde se concluye que los preceptos que permiten la vida sociopolítica del hombre, materializados en derechos y leyes, se entienden como el fundamento de su exigibilidad y garantía. 
Si bien se plantea que las pretensiones metodológicas y políticas del positivismo jurídico se entienden en el marco de una traducción real de los fenómenos sociales y los intereses políticos de una comunidad en particular, su desarrollo conceptual ha generado un divorcio con los presupuestos morales de la vida política, ya que estos últimos -los valores morales-, a la luz de un análisis cientificista de las normas sociales, lejos de explicar las lógicas de la funcionalidad política de las leyes, obedecen más a una respuesta emotiva que entorpece la argumentación legislativa. La positivización entonces, se entenderá como un proceso de asimilación donde el derecho se expresa como fenómeno desprendido de las concesiones normativas de la reflexión jurídica que solo alcanza su culmen cuando i) abandona los presupuestos morales de las normas y ii) se reconoce que la legitimidad normativa emana de una concesión normativa, o constitucional, concienzuda, compacta y contemplativa.

Cabe aclarar que la exposición de estas grandes tradiciones, si bien se contrapone sobre todo a la luz de sus presupuestos filosóficos, no pretenden controvertir el grado de correspondencia del derecho a la luz de las problemáticas subyacentes de la dignidad humana. Se trata más de reconocer que los estadios históricos que conforman su discurso evidencian, a su vez, una referencia a los Derechos Humanos como una preocupación emanada desde la contemplación política de los derechos como garantías para el aseguramiento de la vida misma del hombre. Esta contemplación del derecho como reminiscencia de la dignidad humana alcanza grandes momentos de identificación histórica, por ejemplo, en los esfuerzos políticos de los nacientes Estados de la modernidad política.

$\mathrm{Al}$ respecto, entonces, el sistema de representación inaugurado por los norteamericanos se ha reconocido como uno de los insumos políticos más determinantes para la popularización de los valores democráticos y del discurso de los derechos. La forma de instituirse como nación a la luz de su sistema político, el liberalismo, está atravesada por la comunión de un naciente liberalismo que cataliza la dignidad humana y las libertades como garantías de reconocimiento social y político.

La Constitución de los Estados Unidos expresa manifiestamente la protección de varios derechos como fundamento de la vida social. La protección del derecho a la vida, a la libertad, la distribución y autogestión de la administración del poder y la igualdad constituyen la apertura a un entendimiento que generaliza la sensación política de elementos fundacionales para una carta de derechos universales que cobijen la dignidad desde la génesis misma de la actuación estatal. Cabe aclarar que esta pretensión de reconocimiento universal se percibe en la Declaración del buen pueblo de Virginia, un cuerpo jurídico que impulsa la constitución norteamericana y es culmen de las garantías políticas como fuente de legitimación democrática. 
La base de su reivindicación política representó la fuente de inspiración para la posterior constitución nacional. Firmada el 12 de junio de 1776, se considera la primera declaración de derechos del hombre formalmente constituida en la historia de Occidente. Con un corte iusnaturalista, las reivindicaciones sociopolíticas que allí se emiten demuestran una influencia significativa de pensadores ingleses tales como Jhon Locke y Pufendorf y expresan sobre la base de dieciséis artículos, de los cuales los dos primeros enuncian el posicionamiento de los derechos y de la igualdad como presupuestos políticos, que:

Artículo I: Todos los hombres son por naturaleza igualmente libres e independientes y tienen ciertos Derechos Humanos innatos, de los que, cuando entran en estado de sociedad, no pueden privar o desposeer la propiedad y de buscar y obtener la felicidad y la seguridad.

Artículo II: Todo poder es inherente al pueblo y, en consecuencia el acusado tiene derecho a saber la causa y la naturaleza de la acusación, a ser careado con sus acusadores y testigos, a pedir pruebas a su favor nadie sea privado de su libertad, salvo por mandato de la ley del país o por juicio de sus iguales (ONU, 1948).

Cabe decir que, si bien su reconocimiento ha sido menguado por la aparición de la Constitución Política norteamericana, su fuerza discursiva convence a federalistas y antifederalistas para el acuerdo sobre las enmiendas que consolidan la pacificación y posterior integración de los Estados.

En otras latitudes, los procesos de revolución social vividos en Francia comienzan a provocar serios cuestionamientos de las estructuras políticas medievales. Con una burguesía cansada de la hegemonía politicosocial de la nobleza, con serias dificultades en términos de distribución de la riqueza y, sobre todo, de la capacidad de acción y decisión de las clases sociales, esta nación se adentra en un proceso de reivindicación de la persona como un sujeto instituido por derechos (Angarita, 1997, p. 15).

Influenciada por el enciclopedismo y la Ilustración alemana, esta declaración le otorga a los derechos su conocido estatus de fundamentales y universales en un movimiento dialéctico que fortalecería, por un lado, la reflexión constitucional desde la cohesión política de las normas prescriptivas y, por otro, las discusiones sobre las garantías constitucionales como epicentro del relieve político de los derechos. Pero su influencia no solo hizo mella en la discusión constitucional; se verá que el alcance normativo de la Francia postrevolucionaria comprometerá las bases mismas de la teoría del Estado, del posterior derecho internacional y, por supuesto, de los Derechos Humanos. En resumen, dictada el 26 de agosto de 1789, La Declaración De Los Derechos del Hombre y del Ciudadano se comprenderá como la Constitución Política de la modernidad que consolida los presupuestos de exigencia y reconocimiento social sobre la base de la libertad, la igualdad y la fraternidad. 
Hasta aquí se mencionan las dos tradiciones principales y dos de los hechos históricos que más le han aportado a la idea de los derechos como fundamento catalizador de lo político que lubrica la asimilación universal del reconocimiento del hombre. Pero esta reconstrucción exige un estadio más. A principios del siglo XX, el mapa político del planeta se estremeció ante la lógica de la internacionalización, y con ello, con la ampliación contemplativa de los presupuestos democráticos y constitucionales. Desde allí, los derechos económicos, culturales y sociales toman una particular importancia en el léxico de los derechos. Este hecho queda evidenciado en la ardua preocupación sobre fenómenos como el armamento bélico, la paz internacional, la esclavitud, el reconocimiento de la diversidad cultural, entre otros.

Pero fueron los estragos de la Primera Guerra Mundial y el subsecuente Tratado de Versalles los que consolidan la idea de reorganizar el mapa de las relaciones internaciones con el fin de orientar la política con miras al respeto y a la resolución de los conflictos al margen de la guerra. A efectos suyos, entonces, se agita el vínculo del ser humano como una categoría de injerencia internacional, la vinculación de los derechos laborales en la escena democrática y, por supuesto, el compromiso de la convivencia entre los Estados, no obstante, estas intenciones políticas no estarían más lejos de materializarse. Después de la tercera década del siglo XX, el escenario internacional presenció cómo una a una, sus declaraciones democráticas sobre el respeto y reconocimiento político se difuminaba en el aire ante la consolidación de grandes dictaduras y los estragos de la guerra. Un escenario catastrófico que puso en jaque los postulados de la modernidad al destruir los ideales políticos de los Estados y los presupuestos emancipatorios del hombre racional.

Ahora bien, más allá de los desaciertos políticos que el holocausto evidencia, se empieza a conformar una nueva fuerza política internacional cuyos fundamentos se dan en un nuevo compromiso de paz marcado por una concesión negativa de la paz dictada por la prohibición de la guerra como método para la resolución de los conflictos dentro de o entre los Estados y, por supuesto, en la creación de la Organización de las Naciones Unidas a finales de 1945.

Después de esta exposición histórica, cabe señalar que los Derechos Humanos arriban en el marco de exposición de la ONU a partir de tres tipos: i) los derechos civiles y políticos: denominados derechos de primera generación, parten de la asimilación constitucional y de los procesos sociales desde el siglo XVIII y XIX tales como el derecho a la vida, el derecho a no ser esclavizado, a la familia, a la libertad de conciencia, al debido proceso, a la personalidad jurídica, entre otros; ii) derechos económicos, sociales y culturales: entendidos como aquellos derechos que se consolidaron desde las corrientes socialistas respecto a los embates de la revolución industrial, y en definitiva sobre la desigualdad 
social de las relaciones políticas. En su haber se cuenta el derecho a condiciones dignas de trabajo, al descanso, a librarse del hambre, a la salud, a la protección de la familia, a la orientación y formación profesional, y al goce general de los derechos. Cabe decir que estos derechos tienen un acento programático, esto es, que representan programas que los estados deben alcanzar en la medida de sus alcances institucionales y políticos; iii) los derechos de la solidaridad: aquí se contemplan el derecho a la libre determinación de los pueblos, derecho al desarrollo, a la paz, al medio ambiente y a sacarle provecho al patrimonio de la humanidad (Angarita, 1997, p. 6).

Si bien toda clasificación recae irremediablemente en una jerarquización, una de las características esenciales de los Derechos Humanos es su indivisibilidad, su correlación e interdependencia. Y aunque se señala sistemáticamente que existe una suerte de preeminencia de unos sobre otros, por ejemplo, de los derechos civiles y políticos sobre los derechos de solidaridad, este hecho obedece más a su madurez histórica -por la exigibilidad prolongada de estos derechos en el tiempo-y jurídica que a alguna estratificación explícita.

\section{Los Derechos Humanos como manifiesto político de la humanidad}

Se han mencionado los aspectos más importantes de la tradición de los Derechos Humanos a partir de los momentos más significativos de su transformación sociohistórica. Ante todo, es menester señalar, pues, que los Derechos Humanos se ciernen en el epicentro de un sistema democrático eminentemente liberal. Si bien otras tradiciones han aportado de cierta manera a su comprensión, como las premisas de reconocimiento desprendidas y reconocidas desde los sistemas socialistas, su discurso, sus herramientas políticas y la institucionalidad que le cobija se despliegan en un contexto democrático. Que su apellido sea liberalismo, conlleva dos serias implicaciones que deben ser mencionadas.

En primer lugar, que el discurso del liberalismo político exige que la lectura histórica del reconocimiento de los Derechos Humanos sea concebido como un triunfo de los valores democráticos, que sus luchas continuas en el tiempo significan una reivindicación de la dignidad humana como una lucha ferviente para alcanzar una idea fundamentada en el respeto por el otro o, incluso, que la funcionalidad política de los Derechos Humanos se entienda como una fuerza discursiva e institucional que controla el poder de los Estados convirtiéndolos en sujetos judicializables, un hecho que puede ser enmarcado en la justificación filosófica del liberalismo mismo, esto es, como un sistema político que concibe la presencia estatal como un mal necesario al que hay que mantener a raya para que no violente la libertad del individuo (Angarita, 1997, p. 18).

En segundo lugar, que los Derechos Humanos albergan todos los males atribuibles a la democracia liberal, a saber, que ha consolidado, de la mano del 
capitalismo, un sistema inequitativo, desigual y agresivo contra el individuo; que su discurso ha posibilitado un chantaje político sobre ciertas naciones; que su funcionalidad política e institucional ha servido a las grandes potencias brindándoles, incluso, una posición de privilegio que extiende las lógicas del colonialismo sobre el tercer mundo (De Sousa, 2014, p. 8).

Frente al primer punto, hay que decir que la comprensión histórica de los Derechos Humanos como un consolidado eminentemente democrático y liberal le concede una lectura política de denuncia sin precedentes históricos. Si bien la globalización, los medios de comunicación y los avances tecnológicos se han encargado de evidenciar problemáticas de injerencia mundial, actualmente no hay un ente político con dimensiones internacionales que se encargue de denunciar y judicializar los crímenes a manos de los Estados y los agentes pertenecientes a este, salvo aquella función que se ejecuta desde la ONU y los Derechos Humanos. No existe una entidad u otro discurso con la efectividad política que contemple problemáticas vinculantes de interés planetario, tales como la crisis ambiental, la pobreza, la lucha contra el terrorismo, la desaparición de las especies y, por supuesto, el aseguramiento de la dignidad humana como premisa política (De Sousa, 2014, p. 10).

Al otro lado se tiene la crítica profunda de que su accionar institucional deviene del control político de las grandes potencias, en cuyo caso, más allá de generar condiciones de reconocimiento, su discurso ha deslegitimado las luchas que se han dado desde abajo, esto es, fuera de la comprensión política de encuadre estrictamente democrático (Rajagopal, 2005, p. 10).

Podría hacerse una lista interminable de beneficios y perjuicios de los Derechos Humanos. Pero algo es cierto, estos representan hoy día un discurso político sine qua non es posible leer las contingencias actuales y las problemáticas sea de orden estatal o de orden internacional. Es claro entonces que, si bien los Derechos Humanos representan un discurso que ha dictado gran parte de las discusiones políticas de la actualidad, también es menester señalar sus problemáticas más sensibles en el orden filosófico, que al caso, corre por cuenta del afianzamiento de una concepción política eurocéntrica en la lectura de los derechos. Esta fuerza discursiva que denuncia la hegemonía de los Derechos Humanos se recrudece al señalar la incapacidad institucional para combatir los perjuicios de uno de sus vecinos ideológicos, a saber, el capitalismo (De Sousa, 2002, p. 65).

Es innegable que los Derechos Humanos, como lenguaje de la dignidad humana, lograron abrirse paso entre muchas otras expresiones. En ese marco se hace más que legítima la pregunta sobre si los Derechos Humanos son eficaces para la lucha de los excluidos, los explotados y los discriminados, o si, por el 
contrario, se evidencia una suspensión sospechosa de la misión que históricamente se le han otorgado en la reivindicación de aquellos que se encuentran en posiciones desfavorecidas.

Desde el culmen de la Segunda Guerra Mundial se le ha encomendado esta función a los Derechos Humanos pero, para pensadores como Ernst Bloch (2011), el arraigo de los derechos conlleva una lucha social por la hegemonía política y económica, no por la dignidad humana. Así, pues, no está por fuera de los límites de humilde ejercicio de escritura considerar un caso particular que, en sus efectos prácticos, puede ayudar a responder por el servicio que prestan los Derechos Humanos a los fines de defensa de la dignidad humana.

\section{Verbigracia, Luigi Ferrajoli: la justicia penal transicional para la Colombia del posconflicto y las garantías para la paz interna}

Puesto sobre la premisa de la defensa de los Derechos Humanos, el caso particular del proceso de paz llevado a cabo entre el Gobierno colombiano y las FARC engrana numerosos componentes que, desde un marco de tratamiento teórico puede ofrecer las dimensiones que limiten las justas medidas para el aseguramiento de la paz y, por ende, de los Derechos Humanos. En este sentido, toma la bandera de la teoría jurídica el italiano Luigi Ferrajoli quien, en su texto $\mathrm{La}$ justicia penal transicional para la Colombia de posconflicto y las garantías para la paz (2016), enmarca, con el lente de la teoría general del derecho, los principales requerimientos jurídicos y las garantías sobre las cuales debe considerarse el establecimiento de una justicia penal transicional para una problemática de conflicto de vieja data y que no ha parado de repercutir en la realidad social y política del país en las últimos seis décadas.

Así, establece el italiano, una premisa fundante de cualquier justicia de transición a la paz, a saber, que la paz es el valor supremo, en tanto que representa y contiene en consecución todos los valores constitutivos de la convivencia civil y de los demás valores políticos. De tal manera que, apelando a la evidencia kelseniana ${ }^{11}$, el tratamiento de los Derechos Humanos que se establece en estas líneas se enmarca en tal defensa de la paz como el valor supremo sobre el que debe estar fundada cualquier teoría jurídica o política, y a cuya materialización deben apuntar todos los Estados en tanto dicha evidencia dicta que la guerra es muerte, vejamen y violación de los valores constitutivos del fin práctico de cualquier conglomerado social.

En el orden de la evidencia, si se quiere, el mismo Thomas Hobbes (2003) ya había establecido la necesidad de erradicar una de las principales características

\footnotetext{
Para un tratamiento a profundidad de la consideración de la evidencia y argumento fundacional del establecimiento de la paz en Kelsen, véase Kelsen (2003).
} 
del estado de naturaleza, el bellum omnium contra omnes, para lograr el establecimiento del Estado civil un requisito no negociable dentro de los términos del contrato social y, en general, del aparato jurídico y su institucionalidad. Así, para el caso colombiano, como lo expone el mismo Ferrajoli, la paz está establecida dentro de la Constitución Política de Colombia, en el artículo 22, como un derecho y un deber de obligatorio cumplimiento.

Un derecho de la persona y, por ende, un deber correspondiente de la esfera pública, que es el principal deber que el Estado tiene que alcanzar. Consistiendo, el derecho a la paz, en un derecho fundamental, como cualquier derecho fundamental, es contra mayoritario, cuya actuación es "deber de obligatorio cumplimiento", incluso contra la voluntad de la mayoría. Por esto sería impropio e inaceptable someter la paz, o sea la solución pacífica negociada del conflicto a cualquier tipo de consulta popular (Ferrajoli, 2016, p. 148).Con esto, lo que se enmarca en el argumento del italiano es, en última instancia, la necesidad de pensar las categorías que configuran los derechos -cualesquiera que sean los adjetivos que se les adjudiquen-y los valores constitucionales que pugnan por ellos sobre la evidencia que, en su incumplimiento, permite avizorar las violaciones a los Derechos Humanos mismos y, por el mismo argumento, resulta inaceptable someter la paz, que es el valor fundante de la vida civil, a un juicio mayoritario, en tanto su consecución es ya el fin hacia el que deben apuntar todas las instituciones del aparato estatal.

Es, entonces, sobre esta premisa que se instaura la defensa ferrajoliana del valor de la paz. Pero, en el caso particular de una justicia transicional para la finalización del conflicto en Colombia, ¿cuáles deben ser los términos especiales necesarios para la realización de una justicia de transición a la paz? ¿Cuál debe ser el tratamiento, dentro de tales términos, que se ofrezca a los principales actores del conflicto? Y ¿cuáles deben ser las garantías jurídicas que se ofrezcan a las víctimas del conflicto? Son apenas algunas de las cuestiones a considerar dentro del margen garantista sobre el que se encuadra la teoría del italiano. Ahora, la evidencia que supera a la forma, en este tipo de aspectos, puede ser respondida por el mismo Ferrajoli, así:

Por lo tanto, la realización de la paz y el "nunca más" a la guerra deben representar ya sea sobre un plano teórico y filosófico o sobre aquel del derecho positivo, un objetivo político y una obligación jurídica prioritaria sobre cualquier otra: un objetivo, entonces, que debe ser alcanzado a cualquier precio. Preguntémonos entonces: ¿cuál es el precio que se debe pagar por este objetivo? El precio es, precisamente, la renuncia a someter a los combatientes a la justicia penal ordinaria y por lo tanto la estipulación, para ellos, de un modelo diferente de justicia: el modelo, que en Colombia se ha llamado justicia transicional (Ferrajoli, 2016, p. 148).

Según se ha dicho, entonces, esta justicia especial debe considerar el establecimiento de la paz como valor supremo y presupuesto de cualquier tipo 
de orden judicial. Además, la justicia transicional debe apuntar a un único fin claro y delimitado por la contingencia que la genera que, para el caso particular del acuerdo de paz entre el Gobierno de Colombia y las FARC, es la finalización definitiva del conflicto armado y la pacificación de todos los combatientes, de tal manera que no haya lugar a una proliferación de rencores y deseos que venganza que posibilitaran la reapertura de nuevos conflictos en el panorama nacional.

La justicia de transición a la paz, entonces, no puede ser dictada por la justicia ordinaria por dos razones delimitadas por el italiano: la primera razón, de carácter jurídico, consiste en que los crímenes realizados en guerra por los alzados en armas no puede ser juzgada por la justicia ordinaria, en tanto lo apremiante de la resolución del conflicto se pone por encima de la norma misma en lo que se refiere al fin de la guerra, la segunda razón, de carácter político, consiste en que no puede alcanzarse una paz estable y duradera en el país, tratando a los diferentes combatientes del conflicto colombiano como delincuentes ordinarios y a los vencidos juzgándolos como criminales.

Ahora, las acciones de guerra, si se pretende la finalización efectiva de un conflicto, solo pueden ser juzgadas por el derecho bélico humanitario. Con lo que, en una justicia de transición a la paz deben ser juzgados solo los crímenes de guerra y los crímenes contra la humanidad y, dentro de estos, principalmente, los que atentan contra la población civil ${ }^{22}$. Pero, con estos, también hay que aclarar que solo los principales responsables de tales crímenes en contra de la humanidad son los que deben ser sometidos al juicio de una forma de justicia de transición a la paz como la que aquí se debe enmarcar.

Aclarado y delimitado, de esta manera, el objeto de la justicia transicional, preguntémonos entonces: ¿en qué forma este tipo de justicia se distingue y tiene que distinguirse de la justicia penal ordinaria? Esencialmente en un punto, lógicamente consecuente con las dos razones antes mencionadas que justifican su adopción: su carácter no "retributivo", no punitivo, sino sencillamente "reparador" y "restaurativo". "Justicia de reparación" ha sido llamado efectivamente este tipo de justicia, basada en el reconocimiento de valores morales y políticos no menores que la justicia retributiva y el severo castigo de los culpables: la reconciliación nacional, la reparación de las injusticias y, sobre todo, la reconstrucción de la verdad histórica, que se logra dando la palabra a las víctimas, reconociendo públicamente sus sufrimientos y por lo tanto rehabilitándolas en su dignidad de personas (Ferrajoli, 2016, p. 150).

En el marco defensorial de los Derechos Humanos, sobre la base de su acepción iusnaturalista, una justicia transicional tal cobra un valor capital en el

2 Aquí, se consideran todos los crímenes estipulados en el artículo 5 del estatuto de la Corte Penal Internacional aprobado en Roma el 17 de julio de 1998, así, deben considerarse masacres, violaciones, secuestros, reclutamientos forzosos efectuados por todos los actores armados del conflicto. Así, no se consideran solo los crímenes realizados por las FARC sino, también, los crímenes realizados contra el, en su momento, grupo guerrillero. 
establecimiento de una paz estable y duradera, en tanto exige una reconstrucción de la verdad entorno a los crímenes realizados por todos los actores de la guerra, una toma de responsabilidades de las atrocidades en la guerra por parte de los mismos y, con esto, se configura un escenario social de resarcimiento de las víctimas que pueda erradicar los deseos de venganza, los odios, rencores y, con ellos, las posibilidades del surgimiento de nuevos enfrentamientos bélicos.

Desde otra perspectiva, además, al resaltar la comprobación de la verdad y la atribución de responsabilidades en los crímenes de guerra, en ningún caso el establecimiento de una justicia especial para la paz representa un marco de impunidad dentro del proceso de paz llevado a cabo en Colombia ${ }^{33}$. Una justicia especial para el nunca más, entonces, solo puede considerarse como un escenario para la impunidad en tanto que no ofrezca los mecanismos juridicopolíticos para el establecimiento de la verdad, la atribución de responsabilidades de los crímenes de guerra, la reconciliación y el resarcimiento de las víctimas del conflicto armado.

Ahora, en tanto que la efectiva constitución de una paz estable y duradera depende de la reconciliación y la construcción de una memoria del conflicto, la justicia transicional por la cual apeló Ferrajoli en su texto se consolida en términos procesuales más no punitivos. La ejecución de los respectivos procesos de atribución de los delitos por parte de los agentes armados es, en última instancia, lo que puede posibilitar el establecimiento de una memoria que configure los fines de una sociedad que plantea nuevas salidas al conflicto y se reconcilia como nación.

\section{¿Cuáles garantías para la paz?}

Como ya se ha dicho, una justicia transicional del tipo de las exigencias del conflicto colombiano, debe tender a la reconciliación y, por tanto, a la verdad, por lo que se hace necesario un cierto grado de indulgencia en las condiciones de los juicios punitivos que en ella se enmarquen. Pero, para lograr la materialización de los escenarios propicios de reconciliación y verdad, es preciso soportarlos sobre la base sólida de las respectivas garantías que permitan su efectiva ejecución. Sobre tamaño supuesto, necesario para el sostenimiento, mantenimiento y la consolidación de la paz como requisito en un marco defensorial de los Derechos

3 En Ferrajoli (2016), pueden encontrarse también referencias precisas a los casos exceptuados para el tratamiento de este tipo de crímenes, expuestos así: "Se trata de un argumento jurídico no decisivo, pues este principio en efecto admite excepciones, con base en el mismo derecho Internacional. El artículo $6^{\circ}$ par. $5^{\circ}$ del II protocolo adicional de 1976 del convenio de Ginebra de 1949, dedicado específicamente a la "protección de las víctimas de los conflictos armados sin carácter Internacional" establece en efecto que, "a la cesación de las hostilidades, las autoridades en el poder procurarán conceder la amnistía más amplia posible a las personas que hayan tomado parte en el conflicto armado o que se encuentren privadas de la libertad, internadas o detenidas por motivos relacionados con el conflicto armado". 
Humanos, Ferrajoli establece tres garantías específicas sobre las que deben fundarse los principios que aseguren los términos del acuerdo, a saber:

La asimetría entre Estado de derecho y violencia extra-legal: considerar esta asimetría implica, grosso modo, establecer un principio sobre el cual se conciba una horizontalidad en los discursos políticos de todos los actores del conflicto. Reconocer la diferencia entre los términos de una civilización del derecho y una incivilización de la guerra implica poner los pies sobre un terreno llano a partir del cual conformar una efectiva reconciliación fundada en la construcción de la verdad del conflicto. Así, no puede existir, en los términos de un proceso de paz, ni en su ejecución, ningún tipo de estado de excepción o de violencia por parte de los agentes institucionales, solo espacios para la conformación de una memoria territorial con el fin último de no volver al conflicto. Ahora, para la claridad, en los términos desarrollados por el italiano, solo las garantías penales y procesuales que puede ofrecer un Estado de derecho pueden permitir el mantenimiento de los debidos procesos que evitarían una vuelta de tuerca al arbitrio de la violencia.

Es justamente la experiencia institucional colombiana de estos últimos quince años, considero, la que provee, si fuera necesario, una confirmación del valor político y moral de esta distancia y esta asimetría. Debemos en efecto reconocer -como me parece sea ya comúnmente reconocido- el fracaso de la así llamada "política de seguridad democrática" promovida en Colombia en la primera década de este siglo y que consistía en la respuesta simétrica del Estado a la guerra con la guerra, además de las medidas excepcionales de carácter liberticida (Ferrajoli, 2016, p. 153).

Con argumentos de este talente, la construcción teórica ferrajoliana es la confirmación de una cierta necesidad de preponderancia de la discusión política llevada a la acción sobre los límites procesales y punitivos de un Estado de derecho para conformar los valores politicomorales que posibiliten el reconocimiento de los agentes del conflicto en lugar de suprimir la violencia con más violencia ejercida, desde el seno de la institucionalidad, por parte de las Fuerzas Armadas del Estado.

El desarme de la sociedad civil y el monopolio policial de la fuerza: el segundo orden de garantías para el aseguramiento y mantenimiento de la paz que establece Ferrajoli puede entenderse, en términos hobbesianos, como la entrega total y sin restricción de las armas, no solo por parte de los grupos armados implicados en el conflicto, sino de la sociedad civil en general. Una efectiva dejación de las armas y la generación de un marco político para la no fabricación ni distribución de las mismas, son requerimientos que, aunque el mismo autor reconoce que no representan objetivos realizables hoy en ningún 
país del mundo, establecería los términos necesarios para la efectiva puesta en marcha del organigrama juridicopolítico de un acuerdo de paz.

Es esta una cuestión de fondo, sobre la que he insistido muchas veces y que va bien más allá del problema de la pacificación nacional en Colombia. Cada año, en el mundo, hay centenares de millares de homicidios: exactamente 437.000 solo en el 2012, la mayor parte con armas de fuego; sin contar los muertos todavía más numerosos (se calcula aproximadamente unos dos millones) provocados por las muchas guerras civiles o entre Estados (Ferrajoli, 2016, p. 156).

Ahora, más allá del carácter fáctico de posibilidad que pueda tener la exigencia planteada por Ferrajoli, lo que se busca en este apartado es demostrar la envergadura de las consecuencias de la industria armamentista en las pretensiones de consolidación y mantenimiento de un proceso de paz como el desarrollado entre el Gobierno colombiano y las FARC. Añadido a la prohibición sin excepciones de las armas, en consideración a la problemática propiamente colombiana del conflicto, el italiano propone la idea de una política racional, que considere volcarse sobre los valores de la legislación actual y, en relación al narcotráfico -el principal factor movilizador del conflicto armado- que legalice y, por tanto, controle el comercio de drogas duras, su consumo y su producción, con el fin de aportar al progresivo desarme de la población civil y de las macro estructuras que, hoy todavía, participan en la guerra.

La democracia en sus dos dimensiones: la política o formal y la constitucional o sustancial: se trata, en este último orden de garantías, de la exigencia del respeto y la consolidación de una pugna por el mantenimiento de las dos dimensiones fundantes de la democracia en un sentido netamente constitucional. En un primer caso, se habla de la dimensión formal (política) que se manifiesta en la práctica representativa de la ciudadanía en todos los espectros decisionales del ordenamiento jurídico de una nación y, en un segundo lugar, se habla de la dimensión sustancial (constitucional) consistente en el marco normativo particular que regirá la acción decisional.

Así, pues, por una parte, solo la primacía de la institución parlamentaria ${ }^{44,}$ en su forma y método de defensa de los valores democráticos puede establecer

\footnotetext{
Se toma aquí la noción del parlamento, en tanto Ferrajoli pone el tono de sus argumentaciones sobre la idea kelseniana de la democracia, en torno a la cual se expresa así: "Es, en efecto, el Parlamento, como escribió Kelsen, la institución que, a través de la confrontación entre mayoría y minorías 'crea la posibilidad de un compromiso'; donde compromiso significa: posposición de lo que divide los asociados en ventaja de lo que los une y, por lo tanto, recíproca tolerancia. Por esto la mejor forma de democracia, para Kelsen, es la democracia parlamentaria que resulta de la adopción del sistema electoral proporcional: porque, él afirma, 'el entero procedimiento parlamentario apunta al logro de una vía intermedia, de una resultante de las fuerzas sociales antagonistas' que obviamente requiere 'que todos los grupos políticos estén representados en el parlamento en proporción a su fuerza, si se quiere que el parlamento represente la situación de hecho de los intereses en conflicto, lo que es el postulado teórico para alcanzar un compromiso'" (2016, p. 159).
} 
el aseguramiento de los lineamientos enmarcados para que se posibiliten los escenarios pertinentes para lograr una efectiva construcción de una memoria histórica del conflicto, sobre los debidos procesos, necesarios para la consolidación de una paz estable y duradera y, por otra parte, recordando la aparición, por vías parlamentarias, del fascismo y el nacismo, Ferrajoli establece la urgente necesidad de no considerar solamente el aparato representativo y formal de democracia, sin una dimensión que considere la conformación de este marco sustancial de defensa de los principios democráticos y derechos fundamentales enmarcados en la Constitución.

De esta manera, desde el papel del marco juridicopolítico necesario para la consolidación de una paz efectiva, estable y duradera, pensada para el caso específico del conflicto colombiano, esta última exigencia de Luigi Ferrajoli enmarca una reflexión más profunda -en lo que se refiere al establecimiento de una memoria colectiva de la guerra- que simples lineamientos procesales para la consolidación de una empresa burocrática enmarcada en la institución política, a saber, que no puede edificarse la puesta en marcha de un acuerdo para la consolidación y mantenimiento de la paz interna en Colombia si esta no se soporta en las dimensiones formales y sustanciales de la democracia, necesarias, en el marco de un Estado de derecho, para la efectiva erradicación de la guerra por vías políticas, y para el aseguramiento de su mantenimiento en el tiempo, por medio de la construcción de principios sociales orientados a la defensa de los derechos, adjetivados o como se prefiera.

Así, pues, con sus falencias y cuestionamientos, mientras no exista otro discurso orientador con la marcada contundencia y la aceptación de la que gozan los Derechos Humanos será imposible pensar otra forma de comprensión de problemáticas similares a las particulares aquí representadas. Con lo que se considera pertinente hacer una última reflexión: que la argumentación política de los Derechos Humanos y, para el caso particular, del valor supremo de la paz, no puede ser comprendida solo a la luz de su efectividad política o su formalidad jurídica. Los seres humanos son más que una formalidad, y aunque quizás sea imposible interpretar la esencia humana para llevarla a un escenario prescriptivo o institucional, su sola pretensión permite seguir pensando que un mundo mejor, marcado por la paz y la armonía política es posible más allá de los panoramas actuales. Si los mecanismos jurídicos o las contingencias políticas aún no se corresponden con esos ideales que robustecen gran parte de las instituciones —en este caso la ONU — la contemplación del ideal como brújula política ha permitido la consolidación de nuestros proyectos políticos. Esto quiere decir que la defensa y consolidación de los Derechos Humanos y, en ellos, el valor supremo de la paz exige y merece una madurez institucional mayor y una intencionalidad política alejada de los intereses particulares. Así pues, se pretende destacar la función de los ideales utópicos, a veces tan fugaces y tan 
distantes para nuestra realidad política, de aquel reconocimiento. Por lo que cabe resaltar la expresión de Eduardo Galeano respecto a la utopía: "la utopía está en el horizonte. Camino dos pasos, ella se aleja dos pasos y el horizonte se corre diez pasos más allá. ¿Entonces para qué sirve la utopía? Para eso, sirve para caminar" (Galeano, 2012).

Se quiere pensar que actualmente se transita por los senderos de la utopía.

\section{Conclusiones}

Si bien en la política de la polis de la antigua Grecia se encuentran algunas reflexiones en torno a la dignidad humana, su aparición formal se dará en el marco de las tradiciones iusnaturalista y del positivismo jurídico y, naturalmente, bajo el triunfo de la democracia en la modernidad que, en términos políticos experimentó una mutación en el juicio sobre los sistemas sociales, del ciudadano, y de los instrumentos políticos que materializarán la comprensión del derecho y las leyes como insumos de la vida política que lubrican el aseguramiento de la dignidad del hombre y de las condiciones que permiten su despliegue, ya desde lo estrictamente normativo o desde la enunciación de la naturaleza humana.

Con la aparición de la ONU, comienza una nueva comprensión del fenómeno de lo político, y marca tanto el inicio de la era estricta de los Derechos Humanos desde su afianzamiento y respaldo institucional como el crecimiento de organizaciones paralelas que robustecieron la comunidad internacional desde la política, desde lo económico y lo cultural. Entre otras: la Organización de Estados Americanos, la Organización de la Unidad Africana y la OIT (Organización Internacional del Trabajo).

Es cierto, y queda más que demostrado, que los Derechos Humanos mantienen serias dificultades políticas, filosóficas e institucionales. Puede decirse que la correlación de los Derechos Humanos es inexistente, que su andamiaje institucional refuerza la hegemonía de las potencias, que la ONU esconde una lógica de intervencionismo al servicio de intereses políticos, y que su estructura misma no obedece a presupuestos democráticos de representación, pero en la actualidad, incluso para los más escépticos, los Derechos Humanos mantienen una fuerza discursiva, social y política más que considerable para la interpretación de los fenómenos sociales y políticos de la actualidad.

En cualquiera de los casos, la conclusión parece difusa. Si bien a estos se pueden aducir los peores males, el presupuesto de los Derechos Humanos como elemento de reivindicación del hombre reluce desde su fuerza política. La versión política de los Derechos Humanos se encuentra en la idealización de sus presupuestos identitarios. 
Cuando el monopolio de la guerra es ejercido por las fuerzas estatales, puede manifestarse una situación preocupante y limitante de las pretensiones del establecimiento de una paz estable y duradera: si el Estado se pone al nivel de la violencia extralegal y combate con fusiles las masacres generadas con fusiles, la institucionalidad se convierte en un ente generador de una espiral de violencia tan devastadora como el mal que se pretende erradicar y, así, sin la demarcación de una asimetría entre la violencia de los alzados ilegalmente en las armas y las armas de las instituciones estatales, solo se asiste al teatro de la violencia, de una institucionalidad castrada para la construcción de paz y la memoria histórica, que son requisito no negociable de la reparación de las víctimas en el ultraje de la guerra.

Mientras no exista otro discurso con una fuerza y aceptación similar al de los Derechos Humanos no se podrá pensar con otro lente el orden de lo posible en el ámbito político. Si bien se han señalado sistemáticamente sus falencias, parece que su vigencia y actualidad acompañarán por mucho más tiempo el lenguaje y la reflexión de la política internacional.

\section{Referencias}

Angarita, P. (1997). Derechos del hombre y de la mujer: su reconocimiento a través de la historia. Universidad de Antioquia. (Texto inédito, sin paginación).

Asamblea General ONU. (1948). Declaración Universal de los Derechos Humanos. París.

Bloch, E. (2011). Derecho natural y dignidad humana (Trad., F. González Vicén). Madrid: Dykinson.

De Aquino, T. (2007). La monarquía. Ciudad de México: Técnos.

De Hipona, A. (2009). La ciudad de Dios. Madrid: BAC.

De Sousa, B. (2014). Derechos humanos, democracia y desarrollo. Bogotá: Dejusticia.

Organización de las Naciones Unidas. (1998). Estatuto de la Corte Penal Internacional. Recuperado de https://www.un.org/spanish/law/icc/statute/spanish/rome_statute(s).pdf

Ferrajoli, L. (2016). La justicia penal transicional para la Colombia del posconflicto y las garantías para la paz interna. Revista Crítica Penal y Poder, (10), 146-161.

Galeano, E. (2012). ¿Para qué sirve la utopía? Recuperado de: https://www.youtube.com/ watch? $\mathrm{v}=\mathrm{GaRpIBj} 5 \mathrm{xh}$

Hobbes, T. (2003). El Leviatán. Madrid: Losada.

Kelsen, H. (2003). La paz por medio del derecho. Madrid: Trotta.

Organización de las Naciones Unidas. ONU. (1948). Declaración Universal de Derechos Humanos. Recuperado de https://www.ohchr.org/EN/UDHR/Documents/UDHRTranslations/spn.pdf

Rajagopal, B. (2005). El derecho internacional desde abajo: el desarrollo, los movimientos sociales y la resistencia del tercer mundo. Bogotá: ILSA.

Sánchez, P. (1981). Comentarios. En Sófocles (Aut.), Antígona. Madrid: Gredos.

Sófocles., (1981). Antígona. Madrid: Gredos.

Villegas, M. (2014). Sugerencia sobre el derecho natural. Anuario Jurídico y Económico Escurialense, (47), 93-115. 